\title{
An aetiological profile of febrile thrombocytopenia in children
}

\author{
Sujatha Ramabhatta ${ }^{1}$, *Pushpalatha Kariyappa ${ }^{1}$, Bharathi Kondappa ${ }^{1}$, Udaya Kumar Rao ${ }^{1}$, \\ Hareesh Sanikam ${ }^{1}$
}

Sri Lanka Journal of Child Health, 2018; 47(2): 146-148

\begin{abstract}
Objective: To establish the possible aetiology of febrile children presenting with thrombocytopenia.
\end{abstract}

Method: In this observational study, all children, aged 1 month to 18 years, admitted to paediatric wards of the ESIC Medical College \& Postgraduate Institute of Medical Sciences and Research, Bengalaru, India, from October 2012 to September 2013, with fever and thrombocytopenia, were included. A thorough history was obtained and a general and systemic examination done. Routine investigations were done in all cases and specific investigations as and when required.

Results: Of 1551 children admitted with febrile illness during the study period, 306 with thrombocytopenia fulfilled the inclusion criteria. Thirty five percent of children had mild thrombocytopenia. The commonest cause of thrombocytopenia was dengue fever $(83 \%)$. The mortality was low $(0.7 \%)$ and was seen only in dengue fever in our study.

Conclusions: The commonest cause of febrile thrombocytopenia in this study was dengue fever, accounting for $83 \%$ of cases.

DOI: http://dx.doi.org/10.4038/sljch.v47i2.8481

(Key words: Febrile thrombocytopenia, platelets, dengue fever)

\section{Introduction}

Fever in children is one of the most common manifestations of an illness that make parents to seek medical attention early. Every child with fever has to be assessed carefully to find an aetiology ${ }^{1}$. Common causes of fever with thrombocytopenia are infections like malaria, dengue, leptospirosis, viral fever and septicaemia.

\footnotetext{
$\overline{{ }^{1} \text { ESIC Medical College and Post Graduate Institute }}$ of Medical Science and Research, Bengaluru, India *Correspondence: dr.pushpalathaanil@yahoo.in (Received on 13 July 2017: Accepted after revision on 18 August 2017)

The authors declare that there are no conflicts of interest

Personal funding was used for the project.

Open Access Article published under the Creative
}

Commons Attribution CC-BY (cC) (†) License
Thrombocytopenia is defined as a platelet count below the normal range for the population, and a traditional value of 150,000 per cubic millimetre is supported by the National Health and Nutrition Examination Survey as the lower limit of normal ${ }^{2}$.

\section{Objectives}

To establish the possible aetiology of febrile children presenting with thrombocytopenia.

\section{Method}

This observational study was conducted on children admitted to paediatric wards in the ESIC Medical College \& Postgraduate Institute of Medical Sciences and Research, Bengalaru, India, from October 2012 to September 2013. All children, aged one month to 18 years, presenting with fever and thrombocytopenia were included in the study. Children with haematological disorders, malignancies, collagen vascular disorders and those on drugs known to cause thrombocytopenia were excluded from the study. The study was approved by the hospital ethical committee and written consent was taken from all the parents before enrolment. A thorough history was obtained and a general and systemic examination done. Routine investigations were done in all cases and specific investigations when indicated. Investigations included complete haemogram, blood urea, serum creatinine, serum electrolytes, aspartate and alanine aminotransferases, prothrombin time and activated partial thromboplastin time, blood culture, smear and card test for malaria parasite, serological tests to detect dengue, leptospira, chikungunya, enteric fever, rickettsiae, urine analysis, chest radiograph and ultrasonogram of abdomen.

\section{Results}

A total of 2217 children was admitted to the paediatric wards during the study period, of which 1551 had febrile illnesses. Three hundred and eleven $\quad(20 \%) \quad$ children developed thrombocytopenia. Five were excluded from the study, 2 due to leukaemia, 2 due to idiopathic thrombocytopenia and 1 due to systemic lupus erythematosus. The study group thus consisted of 306 children with febrile thrombocytopenia.

One hundred and fifty five $(50.7 \%)$ children were more than 10 years of age, $101(33 \%)$ in the 6-10 year age group, $43(14.4 \%)$ in the $1-5$ year age group and $7(2.3 \%)$ were infants. Of the children, $184(60 \%)$ were males. A definitive diagnosis was 
made in $280(91.5 \%)$ children. Twenty six $(8.5 \%)$ children were diagnosed as probable viral fever after excluding other causes. Table 1 shows the causes of febrile thrombocytopenia.

Table 1

Causes of fever with thrombocytopenia $(n=306)$

\begin{tabular}{|l|c|}
\hline \multicolumn{1}{|c|}{ Cause } & No. of patients (\%) \\
\hline Dengue fever & $254(83.0)$ \\
\hline Viral fever & $26(08.5)$ \\
\hline Enteric fever & $22(07.2)$ \\
\hline Malaria & $03(01.0)$ \\
\hline Hepatitis A & $01(0.3)$ \\
\hline
\end{tabular}

The platelet count was between 100,000$150,000 / \mathrm{mm}^{3}$ in $107(35 \%)$ children, 50,000$100,000 / \mathrm{mm}^{3}$ in $85(28 \%), 20,000-50,000 / \mathrm{mm}^{3}$ in $88(29 \%)$ and less than $20,000 / \mathrm{mm}^{3}$ in $26(8 \%)$ children. Eighty seven (28.4\%) children had bleeding symptoms. Among them, 55 (63\%) had subcutaneous bleeding. Mucosal bleeding, in the form of epistaxis, gum bleeding, haematuria, melaena, haematemesis and intracranial haemorrhage, was seen in 32 (37\%) children.

All children were given supportive and specific therapy based on the diagnosis. Three hundred and four children improved with increase in platelet counts within 4 days to 2 weeks. Two $(0.7 \%)$ children with severe dengue succumbed.

\section{Discussion}

The present study was undertaken to find out the aetiology of febrile thrombocytopenia in the paediatric age group. A systematic analysis showed that infectious diseases constitute nearly two thirds of total childhood mortality globally ${ }^{3}$. Around 65$70 \%$ of inpatient admissions in our hospital were due to infectious diseases. Majority (51.3\%) of the children in the study group were in the age group above 10 years followed by 5-10 year age group implying increased outdoor activity and thereby increased risk of exposure to mosquito vectors as compared to pre-schoolers. Morales AJR et al observed peak incidence of febrile thrombocytopenia in the age group of $3.94 \pm 3.54$ years ${ }^{4}$. Males were more affected in our study similar to many studies done in adults showing increased exposure to mosquitoes ${ }^{5}$.

The aetiology was found to be dengue fever in $83 \%$ of the children in our study with $62.3 \%$ nonstructural protein 1 antigen (NS1Ag) positivity similar to the study by Shankar RR, et al who observed dengue as the cause of viraemia in 52 out of 100 adult patients ${ }^{6}$. Masamatti SS, et al have observed dengue illness in $48.3 \%$ in their study ${ }^{7}$. Bhatnagar MK, et al in their study of fever with thrombocytopenia have observed that $45 \%$ of cases were dengue ${ }^{8}$. Kumar $\mathrm{P}$, et al have observed malaria as the aetiological factor in $32.6 \%{ }^{5}$. Morales AJR, et $a l^{4}$ found thrombocytopenia in $59 \%$ of children with plasmodium vivax infection, while Shetty G, et $a l^{9}$ have observed thrombocytopenia in $71 \%$ of cases diagnosed as malaria. Malaria was seen in $1 \%$ of our study similar to the study by Masamatti SS, et al who observed malaria in $2.3 \%{ }^{7}$. Our low incidence of malaria is probably due to low endemicity in Bengalaru, India.

Typhoid is the fifth commonest cause of infection induced thrombocytopenia (14\%) with malaria, human immunodeficiency virus (HIV), dengue, Epstein Barr virus (EBV) infections superseding typhoid according to a study by Herbinger $\mathrm{KH}$ et $a l^{10}$. Malik AS et al have observed that thrombocytopenia is relatively common in typhoid fever with a reported incidence of up to $26 \%$ in children ${ }^{11}$. Further, it has been considered as a marker of severity of the disease with an increased risk of complications ${ }^{11}$. In contrast, enteric fever was diagnosed as a cause of thrombocytopenia in $7.2 \%$ in our study which is similar to the study by Chandrashekhar et al $(13.4 \%)^{12}$ and the study by Ahmed Y et al $(10 \%)^{13}$. Hepatiits A was seen in $0.3 \%$ of our study as compared to the $5.1 \%$ in the study by Jagadishkumar $\mathrm{K}$ et $a l^{14}$. This could be because of outpatient management of the majority of our children with Hepatitis A where no serial measurements of platelet counts were done. Viral illnesses accounted for $8.5 \%$ in our study similar to the study by Kumar $\mathrm{P}$ et al where undiagnosed viral fevers accounted for $6.3 \%{ }^{5}$. Viruses cause thrombocytopenia either by decreased platelet production or by enhanced platelet destruction ${ }_{\text {sequestration }}{ }^{15}$. Thirty five percent of our children had mild thrombocytopenia with platelet count between $100,000-150,000 / \mathrm{mm}^{3}$ similar to the study by Kumar $\mathrm{P}$ et al who found mild thrombocytopenia in $50 \%$ of the study group ${ }^{5}$. Bleeding was seen in $28.4 \%$ of 306 children with subcutaneous bleed and petechiae in $17.6 \%(63 \%$ of 87 children) in our study. Kumar $\mathrm{P}$ et al also noted bleeding in $11.1 \%$ in their study ${ }^{5}$.

Children diagnosed as dengue fever were given symptomatic treatment and platelet counts were followed up serially. Platelets were transfused to children who had significant mucosal bleed leading to haemodynamic instability or whose counts were less than 10,000 per cubic millimetre ${ }^{16}$. The remaining children in the study group were treated depending on their diagnosis. Most of them recovered and platelets started improving within 4 days to 2 weeks after admission. There were 2 $(0.7 \%)$ deaths in our study and both were in children with severe dengue infection. The main limitation of our study is that it is a single centre, 
hospital based observational study in Bengalaru, India which might not reflect the entire community.

\section{Conclusions}

Common causes of febrile thrombocytopenia in this study were dengue fever $(83 \%)$, undiagnosed viral fever $(8.5 \%)$ and enteric fever $(7.2 \%)$.

\section{References}

1. Parthasarathy A, Gupta P, editors. IAP Textbook of Pediatrics, $5^{\text {th }}$ edition. New Delhi: Jaypee publications; 2013. p 205. https://doi.org/10.5005/jp/books/11894

2. Cheng CK, Chan J, Cembrowski GS, van Assendelft OW. Complete blood count reference interval diagrams derived from NHANES III: stratification by age, sex, and race. Laboratory Hematology 2004; 10:42-53.

https://doi.org/10.1532/LH96.04010

PMid: 15070217

3. WHO/CHERG. Global, regional and national causes of child mortality: an updated systematic analysis for 2010 with time trends since 2000. The Lancet, early online publication, 11 May 2012 https://doi.org/10.1016/S01406736(12)605 60-1

4. Morales AJR, Sanchez E, Vargas M, Piccolo C, Colina R, Marria- Anemia and thrombocytopenia in children with Plasmodium Vivax malaria, Journal of Tropical Paediatrics 2006; 52 (1):49-51. https://doi.org/10.1093/tropej/fmi069 PMid: 15980019

5. Kumar P, Chandra K, A clinical study of febrile thrombocytopenia- A hospital based retrospective study, Indian Journal of Clinical Practice 2014; 24(10) :

6. Shankar RR, Kambdar PK, Dabhi AS, Clinical and laboratory evaluation of patients with fever with thrombocytopenia. Indian Journal of Clinical Practice 2013; 24(4):360-3.

7. Masamatti SS, Vijaya C, Bhat A. Laboratory and etiological profile of febrile thrombocytopenia cases A cross sectional study, National Journal of Laboratory Medicine 2016; 5(3):44-8.
8. Bhatnagar MK, Yadav SK, Jagdish RK. Clinical, haematological and biochemical profile in acute febrile illnesses with thrombocytopenia. International Journal of Medical Science and Clinical Invention 2016; 3(10):

http://dx.doi.org/10.18535/ijmsci/v3i10.03

9. Shetty G, Avabratha KS, Gonsalves S, Dany A, Rai BS. Thrombocytopenia in children with malaria-A study from coastal Karnataka, India. Asian Pacific Journal of Tropical Disease 2012; 107109.

10. Herbinger KH, Schunk M, Nothdruft HD, Von Sonnenburg F, Loscher T, Bretzel G. A comparative study on infection induced thrombocytopenia among returned travellers. Infection 2012; 40(4):373-9. https://doi.org/10.1007/s15010-012-0242-9 PMid: 22350868

11. Malik AS. Complications of bacteriologically confirmed typhoid fever in children, Journal of Tropical Paediatrics 2002; 48:102-8.

https://doi.org/10.1093/tropej/48.2.102 PMid: 12022423

12. Chandrashekar, Anilkumar YC, Kirandeep S, Dalal SS. A study of clinical and laboratory profile of enteric fever in paediatric age group. Int $J$ of Basic and Applied Med Sciences 2013: 3(3): 16-23.

13. Ahmed Y, Idris Y, Sehahatti K. Clinical and laboratory presentation of typhoid fever. International Pediatrics 2001; 16 (4):227-31

14. Jagadishkumar K, Kumar HCK, Manjunath VG, Anitha C, Mamatha SHepatitis A in children- clinical course, complications and laboratory profile, Indian J Ped 2014; 81(1):15-19 https://doi.org/10.1007/s12098-013-1114-8 PMid: 23904062

15. Assinger A. Platelets and infection- An emerging role of platelets in viral infection, Front Immunolo 2014; 5:649. https://doi.org/10.3389/fimmu.2014.00649 PMid: 25566260 PMCid: PMC4270245

16. Dengue: Guidelines for diagnosis, treatment, prevention and control, WHO, Geneva, 2009. 